\title{
Endophytic colonization of tomato plants by Beauveria bassiana Vuillemin (Ascomycota: Hypocreales) and leaf damage in Helicoverpa armigera (Hübner) (Lepidoptera: Noctuidae) larvae
}

\author{
Joelle Toffa ${ }^{1,2^{*}}$, Yeyinou Laura Estelle Loko ${ }^{1}$, Ouorou Kobi Douro Kpindou², Karim Zanzana², Josky Adikpeto',
} Yasmine Gbenontin ${ }^{1}$, Augustin Koudamiloro ${ }^{2}$ and Appolinaire Adandonon ${ }^{3}$

\begin{abstract}
Background: The endophytic capacity of Beauveria bassiana Vuillemin isolates in 2 tomato varieties and their effects on damage and survival of the tomato fruit worm Helicoverpa armigera Hubner larvae were studied. The bioassays consisted of sowing seeds of 2 tomato cultivars soaked for $24 \mathrm{~h}$ in B. bassiana conidial suspension at the concentration of $1 \times 10^{7}$ and $1 \times 10^{9}$ conidia/ml for the isolates $\mathrm{Bb} 115$ and $\mathrm{Bb} 11$, respectively. Ten leaf, stem, and root segments were cut and incubated for assessing the endophytic growth of the fungus. Percentage of leaf consumption and pathogenicity of B. bassiana on $\mathrm{H}$. armigera larvae were estimated.

Main body: The fungus B. bassiana developed endophytically in the 2 tomato varieties and was detected in tomato leaf, stem, and root. However, higher colonization rates were observed in roots than in leaves and stems. The B. bassiana isolate $\mathrm{Bb} 115$ had a greater negative effect on the mean survival times (MSTs) of $\mathrm{H}$. armigera larvae and on leaf consumption for local and improved tomato varieties. In fact, the lowest MSTs were recorded at the concentration of $1 \times 10^{9} \mathrm{conidia} / \mathrm{ml}$ for $\mathrm{Bb} 115$ in $1.5 \pm 0.2$ days, i.e., 7 days less than the surviving larvae of the control group, which MSTs were $8.4 \pm 0.9$ days. Consumed leaf areas by larvae averaged $\left(89.17 \pm 10.33 \mathrm{~mm}^{2}\right)$ at a fungal concentration of $1 \times 10^{9} \mathrm{conidia} / \mathrm{ml}$ for Bb115. It was the best compared to that of untreated control (820.3 $\pm 92.77 \mathrm{~mm}^{2}$ ). The colonization rate of the different plant parts increased with conidia concentration in both tomatoes varieties.
\end{abstract}

Conclusion: This study reported the effect of endophytic colonization of tomato by B. bassiana on the survival of $\mathrm{H}$. armigera larvae and showed that the isolates $\mathrm{Bb} 115$ and $\mathrm{Bb} 11$ could be considered as useful microorganisms for the integrated control of $\mathrm{H}$. armigera.

Keywords: Endophytes, Entomopathogenic fungi, Beauveria bassiana, Tomato, Helicoverpa armigera, Pest management

\footnotetext{
* Correspondence: joelletoffa@gmail.com

'Laboratoire d'Entomologie Appliquée, Université Nationale des Sciences,

Technologies, Ingénierie et Mathématiques (UNSTIM), B.P. 14, Dassa, Republic

of Benin

${ }^{2}$ International Institute of Tropical Agriculture (IITA), 08 B.P. 0932. Tri Postal,

Cotonou, Republic of Benin

Full list of author information is available at the end of the article
}

\section{Springer Open}

(c) The Author(s). 2021 Open Access This article is licensed under a Creative Commons Attribution 4.0 International License, which permits use, sharing, adaptation, distribution and reproduction in any medium or format, as long as you give appropriate credit to the original author(s) and the source, provide a link to the Creative Commons licence, and indicate if changes were made. The images or other third party material in this article are included in the article's Creative Commons licence, unless indicated otherwise in a credit line to the material. If material is not included in the article's Creative Commons licence and your intended use is not permitted by statutory regulation or exceeds the permitted use, you will need to obtain permission directly from the copyright holder. To view a copy of this licence, visit http://creativecommons.org/licenses/by/4.0/. 


\section{Background}

The tomato (Solanum lycopersicum L) is one of the most important and consumed vegetables in the world. In Benin, yields are low and variable due to insect pests attack, with an average of $9.533 \mathrm{~kg}$ per hectare (Assogba Komlan et al. 2016). Tomato producers are facing a significant pressure from insect pests, particularly the damage caused by the tomato fruit worm, Helicoverpa armigera (Hübner) (Lepidoptera: Noctuidae), the major threat to tomato crops throughout the growing season due to its direct damage to the fruits resulting in yield losses ranging from 20 to 60\% (Herrero et al. 2018). Management of the pest depends mainly on using synthetic pyrethroids' application. Moreover, the use of such chemical compounds led to many side effects such as human hazards, toxic residues in food, insect pests' resistance, environment pollution, and loss of biodiversity. Therefore, there is an urgent need to develop an alternative safe control method. Among the most sustainable alternatives, biological control with the entomopathogenic stands out. The fungus Beauveria bassiana (Ascomycota: Hypocreales) is one of the most widely used entomopathogens in the biological control of pests through the direct application of conidia suspension (Douro Kpindou et al. 2012). B. bassiana is a fungal species with an extremely broad host spectrum. It is a wellknown, naturally occurring and environmentally safe biological control agent (Prasad and Syed 2010). Similar to other species of fungi, $B$. bassiana could endophytically colonize plant tissues and negatively affect herbivore species that feed on them. Endophytic microorganisms reside asymptomatically within higher plants, inhabiting leaves, stems, and roots without any apparent harm to the plant. Endophytic fungi are important because they produce secondary metabolites with a range of potential uses in the agricultural and the pharmaceutical industry (Selim et al. 2012).

An endophytic fungus forms a mutually beneficial symbiotic relationship with the plant species. It lives within the tissues of the plant without causing disease; on the contrary, it stimulates its defenses and the plant in return acts as a host. Metabolites produced by some endophytic fungi, as $B$. bassiana, have been reported to influence the reduction of insect infestations on their host plants (Jaber Lara and Ownley 2017). The insecticidal action of endophytic B. bassiana has also contributed to the management of lepidopteran pests. This is most likely due to plant systemic resistance, elicited by these fungi against insect herbivores. Induced systemic resistance (ISR) is an important mechanism by which the whole plant is primed for enhanced defense against a broad range of insect pests (Pieterse et al. 2014). The efficiency with which $B$. bassiana can colonize and induce defense responses in tomatoes to repel pests is still unknown in Benin. However, investigations should continue within the framework of the biological control of insect pests using endophytic fungi.

Thus, it was important to study the endophytic character of isolates $B$. bassiana $\mathrm{Bb} 115$ and $\mathrm{Bb} 11$ on 2 different local and improved varieties of tomato, the most consumed in Benin. The aim of the study was to evaluate the endophytic colonization of B. bassiana in tomato plants and their effect on $H$. armigera survival.

\section{Main text \\ Methods \\ Plant material}

The local tomato variety "Tounvi" and the improved variety "Padma" were used during the bioassays. Both varieties are semi-erect, with a development cycle that elapses from 65 to 90 and 60 to 70 days for local and improved varieties, respectively. The average weights of a tomato fruit is $24 \mathrm{~g}$ and $120-130 \mathrm{~g}$ for local and improved varieties, in that order. Tounvi and Padma are the 2 most produced and marketed varieties in Benin according to their agronomic quality, their color, and resistance to pests such as H. armigera (Assogba Komlan et al. 2016).

\section{Rearing of Helicoverpa armigera}

A rearing colony of $H$. armigera was established at the laboratory by caterpillars collected from tomato fields at different localities in major tomato production areas in Benin. The larvae were placed in plastic containers $(6.5$ $\times 19.5 \mathrm{~cm})$ and reared on an artificial diet under controlled conditions $\left(70 \pm 5 \% \mathrm{RH}, 26 \pm 2{ }^{\circ} \mathrm{C}\right.$, with a photoperiod of L: D 12:12) until pupation (Douro Kpindou et al. 2012). In order to prevent cannibalism, third-instar caterpillars were transferred individually in Petri dishes provided with artificial diet. The artificial diet consisted of bean flour, beer yeast, methylparaben, ascorbic and sorbic acids, streptomycin, formaldehyde, vitamin complex, agar, and distilled water. Diet was replaced every 2 days in order to avoid desiccation; moistened filter paper was placed in each Petri dish (Barrionuevo et al. 2012). Pupae were collected and placed in polypropylene containers $(6 \times 12 \mathrm{~cm})$ until adult emergence. Folded paper was placed inside the cages for egg deposition. Collected eggs were kept until hatching, and then the larvae were reared as described above. Third-instar larvae (L3; $7.4 \pm$ 0.1 days) were used in all bioassays.

\section{Source and production of the entomopathogenic fungi}

The isolates $\mathrm{Bb} 11$ and $\mathrm{Bb} 115$ were obtained from the entomopathogenic fungi (EPF) collection of the Applied Entomology Laboratory and were selected in previous studies for their pathogenicity towards $H$. armigera (Douro Kpindou et al. 2012). The endophytic characters 
of the isolates remained to be demonstrated on different varieties of tomato most consumed in Benin.

Conidia from the 2 fungal isolates were picked from the stock culture and placed onto standard Potato Dextrose Agar (PDA) in Petri dishes $(\varnothing=9 \mathrm{~cm})$ (Becton, Dickinson and Company; Sparks, MD 21152 USA) for subculture and incubated for 14 days at $26 \pm 2{ }^{\circ} \mathrm{C}$ and a photoperiod of 14:10 h (L: D). Then, conidia of each isolate were harvested by scraping them from the PDA, using a sterilized scalpel and suspended in $0.01 \%(\mathrm{w} / \mathrm{v})$ Tween $80^{\circ}$. Conidial concentrations were estimated, using a Neubauer hemocytometer and adjusted to $1 \times$ $10^{7}$ conidia/ml and $1 \times 10^{9}$ conidia/ml for isolates (Posada and Vega 2005).

The concentration of conidia to be used was calculated as follows:

$$
C^{\prime}=\left(C o \times V_{\mathrm{O}}\right) /\left(V \mathrm{o}+V^{\prime}\right)
$$

where $C^{\prime}=$ concentration to be tested, $C o=$ concentration of initial conidial suspension, $V_{\mathrm{o}}=$ volume needed, and $V=$ volume to be added.

The viability of conidia after $24 \mathrm{~h}$ incubation on PDA was $89 \pm 3.7 \%$ and $92 \pm 1.5 \%$ for $\mathrm{Bb} 11$ and $\mathrm{Bb} 115$, respectively.

\section{Treatment with B. bassiana through seed coasting}

The seeds were sown and monitored under greenhouse conditions $\left(26 \pm 5^{\circ} \mathrm{C}, 14: 10 \mathrm{~h}\right.$ photoperiod) until use of the tomato plants. On the other hand, before sowing, the seeds were mixed with a suspension of fungal conidia with a fungal inoculum of $1 \times 10^{7}$ conidia $/ \mathrm{ml}$ and 1 $\times 10^{9} \mathrm{conidia} / \mathrm{ml}$ of each isolate. Then, they were placed on filter paper and kept for $24 \mathrm{~h}$ before sowing (Russo et al. 2015). Experiment consisted of 5 treatments: (i) tomato seeds soaked in $\mathrm{Bb} 11$ at $1 \times 10^{7}$ conidia/ml; (ii) tomato seeds soaked in $\mathrm{Bb} 11$ at $1 \times 10^{9}$ conidia/ml; (iii) tomato seeds soaked in $\mathrm{Bb} 115$ at $1 \times 10^{7}$ conidia/ml; (iv) tomato seeds soaked in $\mathrm{Bb} 115$ at $1 \times 10^{9}$ conidia $/ \mathrm{ml}$; and (v) untreated control. Seeds were sown in 10 pots for each treatment. All treatments were replicated 3 times for each of the 2 tomato varieties.

\section{Assessment of the endophytic colonization B. bassiana}

The methods of Arnold et al. (2000) and Kambrekar and Aruna (2018) were used to re-isolate B. bassiana from inoculated plant organs. For this purpose, all the glassware were sterilized, using an autoclave at $121^{\circ} \mathrm{C}$ for 15 min and then kept in a hot air oven at $55^{\circ} \mathrm{C}$ for $1 \mathrm{~h}$. Then, 10 leaves and roots randomly sampled from inoculated tomato plants were cut in 5 pieces with a sterilized knife under a laminar air flow chamber. The 5 pieces of each organ (leaf, root) variety and 3 replicates per treatment and per variety pieces $\left(3 \mathrm{~cm}^{2}\right)$ were sterilized in $0.5 \%$ sodium hypochlorite for $3 \mathrm{~min}$, then with $70 \%$ ethanol for $2 \mathrm{~min}$, and then washed with sterile water and dried before placing it onto PDA in Petri dishes $(9 \mathrm{~cm}$ diameter). Petri dishes were incubated at room temperature $\left(28 \pm 2{ }^{\circ} \mathrm{C}\right)$ and periodically checked for fungal growth. The purity and sporulation of the culture were checked using a microscope. Colonization of $B$. bassiana was confirmed by microscopic observations (Ma et al. 2008). Petri dishes with B. bassiana were counted for each organ per treatment and per variety.

Percentage of colonization

$=$ no.of segments colonized $/($ total no.of plant sampled segments $\times 100)$

Percent colonization was determined for different plant organs and the most virulent $B$. bassiana isolate with the highest endophytic colonization was determined.

\section{Assessment of leaf consumption and larvae survival in inoculated and untreated tomato plants}

Leaf consumption was assessed by measuring leaf area consumed by each larva in each treatment. The test consisted of feeding 10 third-instar larvae of $H$. armigera for $24 \mathrm{~h}$ on tomato leaves sampled from inoculated and untreated tomato plants of both local and improved varieties. Ten discs of tomato leaves $(3 \mathrm{~cm}$ in diameter) were obtained by cutting sampled leaves and offered each to the $10 \mathrm{H}$. armigera larvae placed in Petri dish $(90 \mathrm{~mm}$ ) (Magrini et al. 2015). The Petri dishes were then incubated for $24 \mathrm{~h}$ at $25^{\circ} \mathrm{C}, 60 \% \mathrm{RH}$. Thus, using a graduated paper, the consumed area was estimated per treatment and per variety (Russo et al. 2015). Experiments were replicated 3 times. In parallel, larval survival and mortality of $H$. armigera larvae was checked daily per treatment and per variety. Leaves were replaced every 2 days until the 10th day after treatment (Ma et al. 2008).

\section{Data analysis}

The percentage of plants colonized by $B$. bassiana was compared using the chi-square test. Data on larval mortality and sporulation rates were processed by analysis of variance (ANOVA), using the general linear model (GLM) procedure of SAS (SAS Institute Inc 2003). Percentages were based on the initial number of larvae exposed. In case of significant $F$ values, means were compared by using SNK (Student-Newman-Keuls). The modeling of the time-dose-mortality data was carried out, using the "Cox regression" model (Statistical Package for Social Science (SPSS) Inc. 1989-2003). Data on leaf area consumed by larva was compared by applying ANOVA, followed by SNK. 


\section{Results}

Endophytic colonization of tomato plants by $B$. bassiana The endophytic colonization of the tomato organs placed onto PDA showed a whitish color, characteristic of $B$. bassiana mycelium. This colonization was also confirmed by microscopic observations. Thus, the presence of $B$. bassiana was confirmed in leaves, stems, and roots of tomatoes with seeds coasting inoculation method. Regardless to the concentration, the $2 \mathrm{~B}$. bassiana isolates were able to colonize endophytically the different organs in both tomato varieties (Fig. 1).

\section{Assessment of leaf colonization by $B$. bassiana}

The fungus presence was detected in tomato leaves at the 2 concentrations of $\mathrm{Bb} 11$ and $\mathrm{Bb} 115$ isolates. However, the colonization rate for the isolate $\mathrm{Bb} 115$ was more efficient, depending of the inoculation concentration and tomato variety. The highest endophytic colonization rates 91.2 and $74.55 \%$ were observed at the local and improved varieties, respectively, at the concentration of $1 \times 10^{9}$ conidia/ml (Fig. 2). After incubation, the lowest colonization for both varieties was registered with the concentration of $1 \times 10^{7}$ conidia/ml of the Bb115 isolate (local variety). For all treatments, colonization of leaves in the local variety Tounvi of $1 \times$ $10^{9}$ conidia/ml of the $\mathrm{Bb} 115$ was significantly greater than colonization of leaves in the improved variety Padma (df $=7.81, P=0.0050$ ) (Fig. 2). Samples from untreated control did not show any fungal colonization. Regarding stem colonization, the fungus was more uniform than for leaves, and the absence of colonization was only recorded by the $10^{7}$ concentration of the $\mathrm{Bb} 11$ strain (Fig. 3). However, non-significant differences were observed between the treatments ( $D F=1, P=0.8266$ ). Colonization rates on the roots showed strong colonization of the fungal isolates unlike those observed in the leaves and stems.
With the improved variety Padma, the highest colonization rates were registered, where the strain $\mathrm{Bb}$ 115 stood out, with 93.51 and $89.3 \%$ for concentrations $10^{9}$ and $1 \times 10^{7}$ conidia/ml, respectively. On the other hand, low colonization of roots was observed in the local variety inoculated with the 2 isolates $\mathrm{Bb} 115$ and $\mathrm{Bb} 11$ at $1 \times 10^{9}$ conidia/ml (Fig. 4). However, non- significant difference was observed between the 2 varieties (DF $=1$, $P=0.2764)$. No endophytic colonization was observed at the control.

\section{Leaf consumption by $\boldsymbol{H}$. armigera and larvae survival}

Statistical analysis showed significant differences $(F=$ 13.66, $P=0.0043$ ) in the consumption of leaves inoculated with the strains of the fungus, which suggests that the endophytic presence of $B$. bassiana reduced the consumption of $H$. armigera. The use of $B$. bassiana as endophytic fungus in tomato induced an overall significant reduction in leaf consumption by $H$. armigera larvae $(F=76.55, P<0.0001)$. However, there was nonsignificant difference between local and improved varieties. On the other hand, in the improved variety, the average leaf area consumed was $32.08 \pm 7.51 \mathrm{~mm}^{2}$ for $\mathrm{Bb}$ 115 at $1 \times 10^{9}$ conidia $/ \mathrm{ml}$ against $730.7 \pm 62.41 \mathrm{~mm}^{2}$ for the untreated control. In the local variety, $H$. armigera larvae consumed an average of $89.17 \pm 10.33 \mathrm{~mm}^{2}$ of the leaf when plants were inoculated with $\mathrm{Bb} 115$ at $1 \times$ $10^{9}$ conidia/ml against $820.3 \pm 92.77 \mathrm{~mm}^{2}$ for untreated control (Fig. 5). The use of B. bassiana Bb 115 induced an overall significant reduction in leaf consumption by $H$. armigera larvae $(F=76.55, P<0.0001)$.

Survival of $H$. armigera larvae was affected at the 2 concentrations of both isolates $\mathrm{Bb} 115$ and $\mathrm{Bb}$ 11, when offered leaves from inoculated plants in both local and improved varieties. Compared to untreated control, the survival of third-instar larvae of $H$. armigera was significantly affected by the isolate $\mathrm{Bb} 115(F=11.22, P<$ 0.0001; $F=47.13, P<0.0001$; in both local and improved

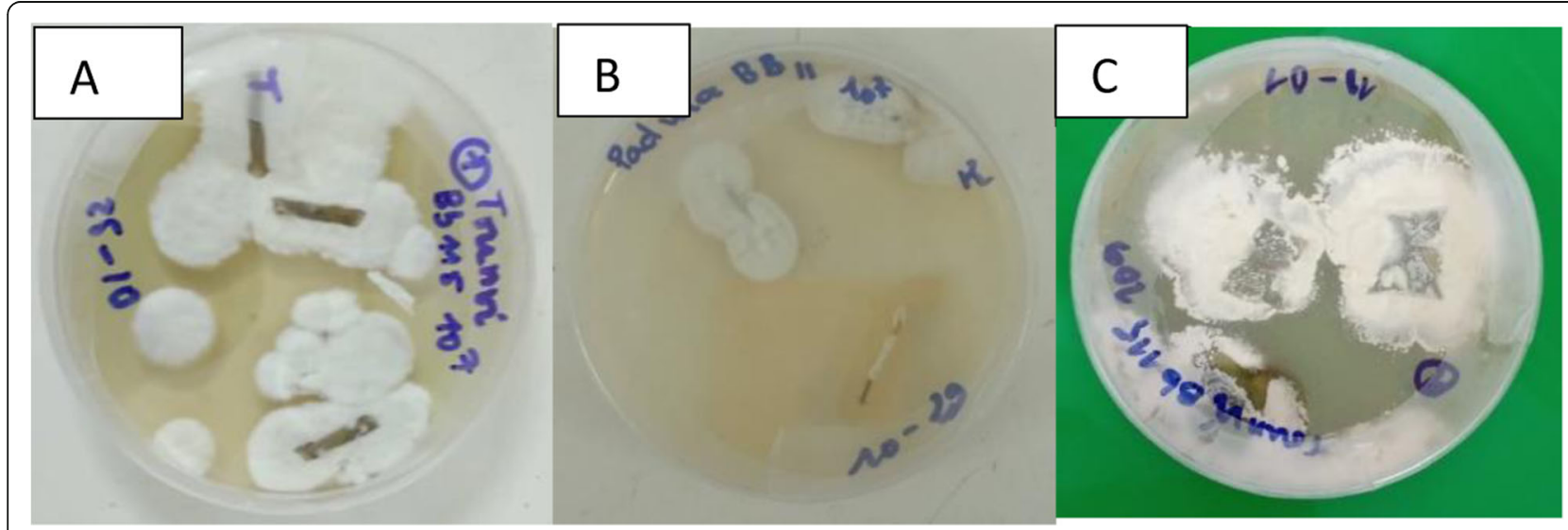

Fig. 1 Colonization of different tomato stem (a), root (b), and leaf (c) segments by Beauveria bassiana after microscopic observation 


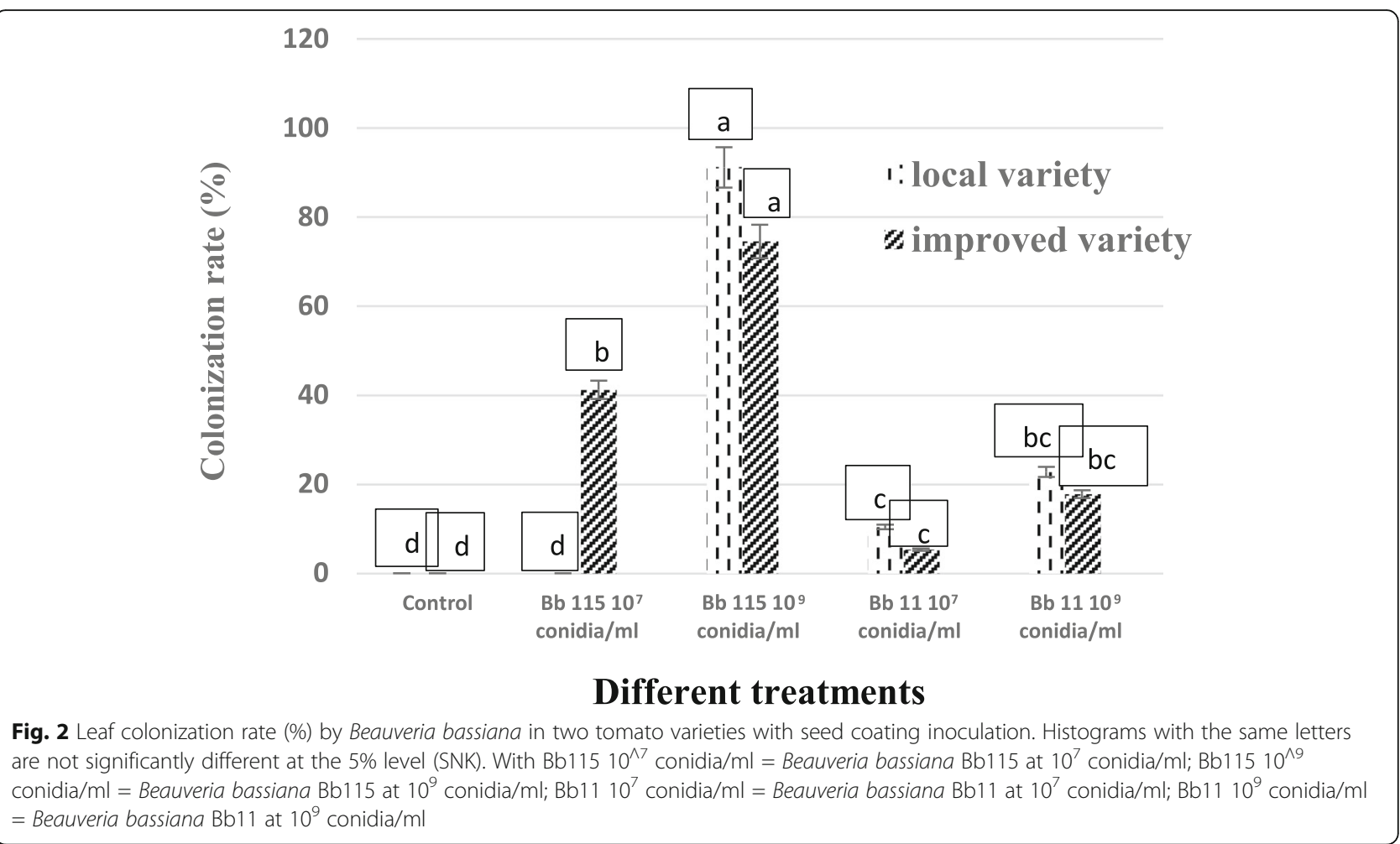

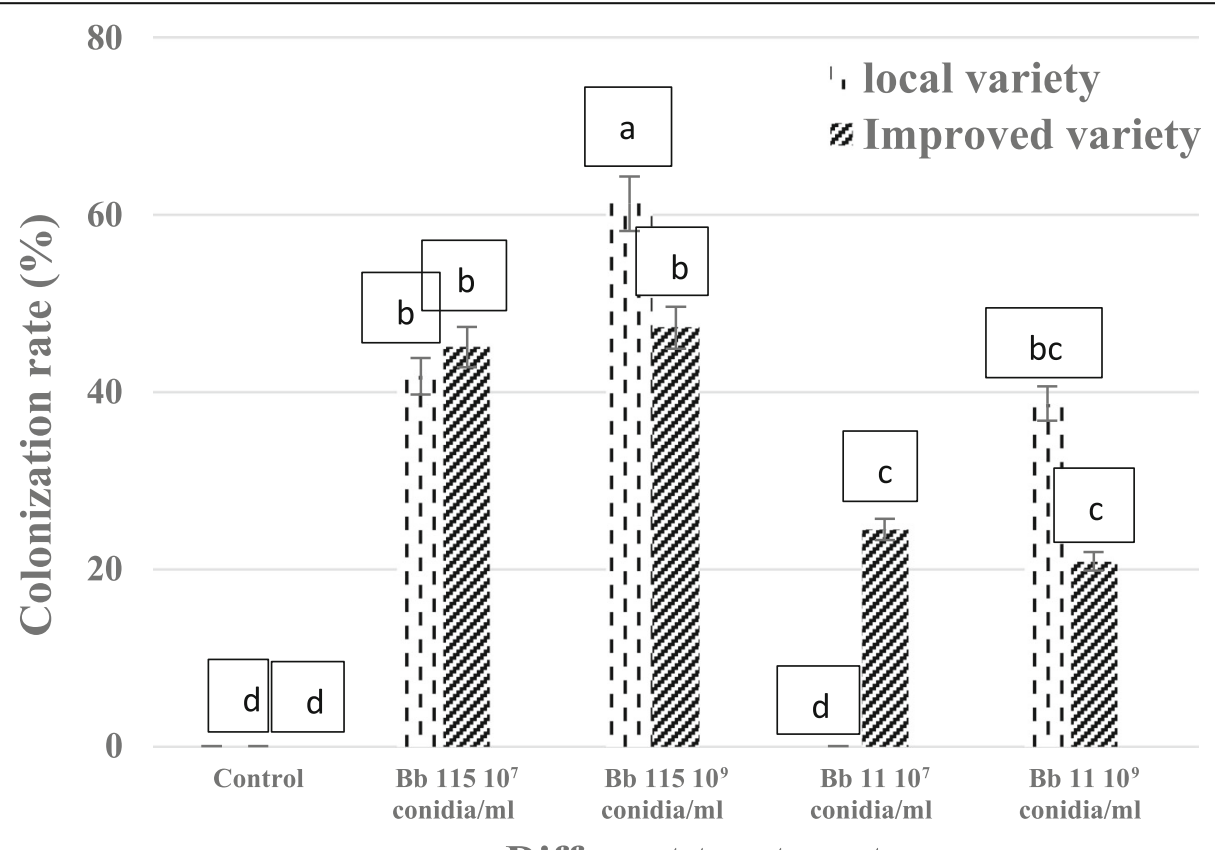

\section{Different treatments}

Fig. 3 Stem colonization rate (\%) by Beauveria bassiana in two tomato varieties with seed coating inoculation. Histograms with the same letters are not significantly different at the $5 \%$ level (SNK). With Bb115 $10^{7}$ conidia/ml = Beauveria bassiana Bb115 at $10^{7}$ conidia/ml; Bb115 $10^{9}$ conidia/ $\mathrm{ml}=$ Beauveria bassiana Bb115 at $10^{9}$ conidia/ml; Bb11 107 conidia $/ \mathrm{ml}=$ Beauveria bassiana Bb11 at $10^{7} \mathrm{conidia} / \mathrm{ml} ; \mathrm{Bb} 11$ 10 $\mathrm{conidia} / \mathrm{ml}=$ Beauveria bassiana Bb11 at $10^{9}$ conidia/ml 


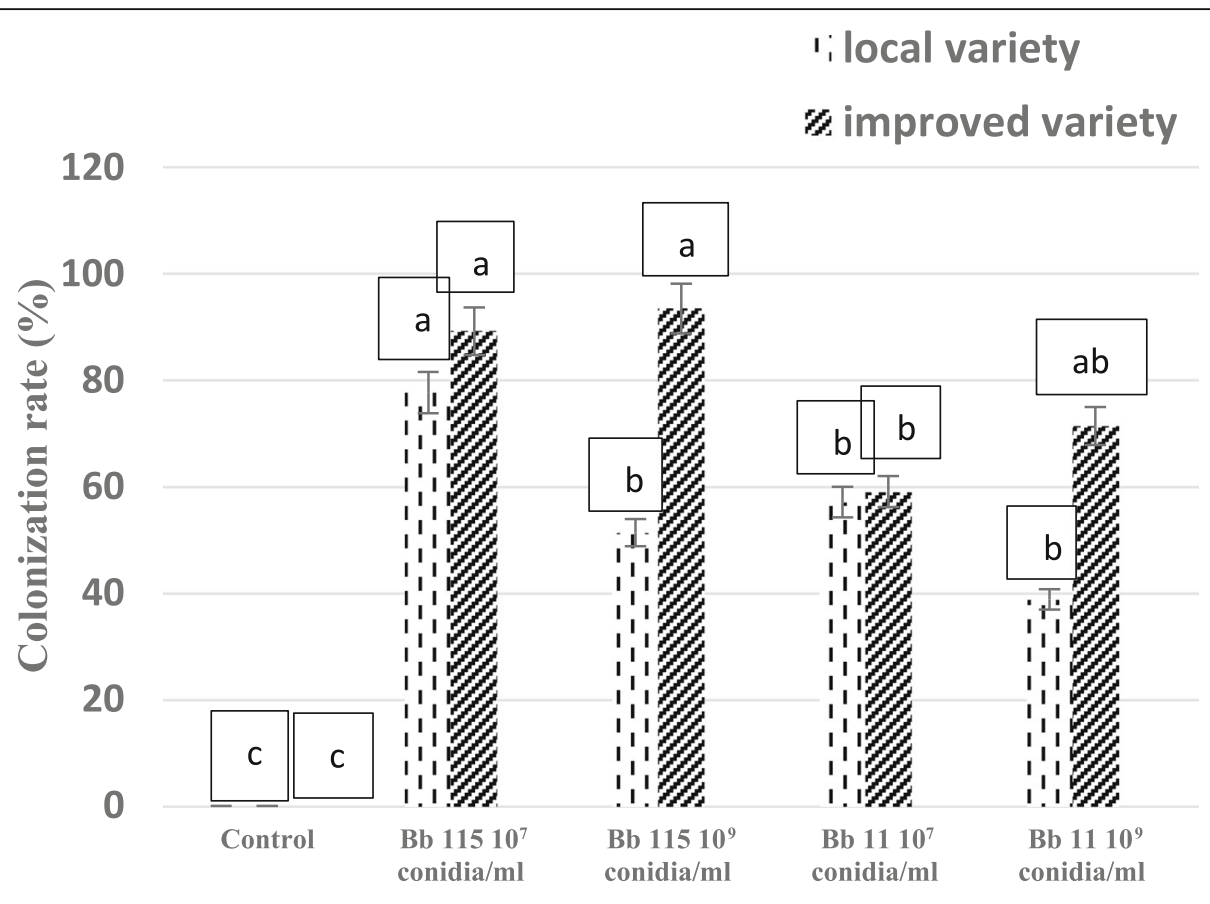

\section{Different treatments}

Fig. 4 Root colonization rate (\%) by Beauveria bassiana in two tomato varieties with seed coating inoculation. Histograms with the same letters are not significantly different at the $5 \%$ level (SNK). With Bb115 $10^{7}$ conidia/ml = Beauveria bassiana Bb115 at $10^{7}$ conidia/ml; Bb115 $10^{9} \mathrm{conidia} /$

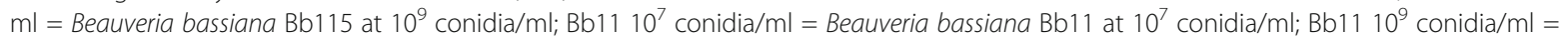
Beauveria bassiana $\mathrm{Bb} 11$ at $10^{9}$ conidia/ml

Bimproved varieties
Bb11 $10^{\wedge} 7$ conidia/ml local varieties


varieties, respectively). On the other hand, regardless to the fungal concentrations, the mean survival times (MSTs) of larvae fed using leaf from the improved variety seemed to be lower than those obtained with the local variety. The lowest MSTs were recorded at the $\mathrm{Bb}$ 115 in $1.5 \pm 0.2$ days at $1 \times 10^{9}$ conidia/ml, i.e., 7 days less than the surviving larvae in untreated control with MSTs of $8.4 \pm 0.9$. However, no difference was observed between the 2 varieties for the MSTs $(F=0.51, P=$ 0.6350) (Table 1).

\section{Discussion}

The development of alternative methods for plant protection has become an attractive option. Among these alternative methods to control crop pests, pathogenic microorganisms including B. bassiana are promising.

The entomopathogen, B. bassiana was isolated from the leaves, stems, and roots of local and improved varieties of tomatoes, indicating the potential of both isolates as effective endophytic agents on tomato plants. Posada and Vega (2005) reported that the endophytism of the fungus $B$. bassiana is not harmful to plants growth. Also, this fungus can colonize various plant tissues without affecting their physiological activities. Similar results have been observed by many authors, where $B$. bassiana has been reported as an endophyte in tomato (Ownley et al. 2004).

Regardless of the inoculation concentration and variety of the tomato plants, the colonization rate of the $B$. bassiana $\mathrm{Bb} 115$ isolate was high in all sampled organs (leaves, stems and roots) than in the isolate $\mathrm{Bb} 11$. This difference could be attributed to the compatibility of $\mathrm{Bb}$ 115 genome which may be more compatible with the internal environment of the plant. Several factors such as the origin, the nature of the entomopathogen, the penetration site, the inoculation method, and the compatibility with the host plant can also influence the endophytic capacity of a fungal isolate compared to another isolate
(Renuka et al. 2017). However, the lower rate of endophytic colonization of $B$. bassiana observed at the isolate $\mathrm{Bb} 11$ at the concentration of $1 \times 10^{7}$ conidia $/ \mathrm{ml}$ could be explained by a limited penetration of germinating conidia in tomato plants.

The colonization rate of tomato by $B$. bassiana increased with the fungal concentration, suggesting that high conidia number resulted in fungal growth within tomato plants. This may be related to high secondary fungal metabolites production in the different plant organs. The endophytic colonization of tomato plants by $B$. bassiana was effective with seed coasting. However, non-significant difference was observed between the tomato varieties demonstrating the capacity of $B$. bassiana to actively penetrate plant tissues, regardless of tomato variety. The highest colonization rate observed in roots than in leaves and stems may be related to their physiological differences and the fungal characteristics. Indeed, colonization started from roots and progressed vertically within stems and leaves with seed coasting.

According to several studies, endophytic fungi present specificity for some plant tissues because they adapted to particular conditions within plant organs. Akello et al. (2007) showed that the seed coasting method allowed the roots to provide a route for the fungus development within plant tissue. On the other hand, Agrios (2005) reported that many pathogenic bacteria and fungi such as $B$. bassiana might enter in plant tissues through natural openings including stomata. Progression of $B$. bassiana within tomato plant could be confirmed with the detection of mycotoxins produced by $B$. bassiana in tomato fruit or seeds.

Moreover, the isolate $\mathrm{Bb} 115$ induced significant decrease in leaf consumption by $H$. armigera larvae than the control. The differences between the improved and local tomato varieties could be explained as the fact that the improved variety was more susceptible to conidia penetration of spores than the local one. Induced

Table 1 Mean survival times (MSTs) in days of third-instar Helicoverpa armigera larvae fed using tomato leaves sampled from tomato inoculated and non-inoculated plants with seeds coasting at different Beauveria bassiana concentrations

\begin{tabular}{lll}
\hline Treatments & \multicolumn{2}{l}{ Mean survival time in days (means \pm SE) } \\
\cline { 2 - 3 } & Local variety & Improved variety \\
\hline Control & $10.7 \pm 1.4 \mathrm{aA}$ & $8.4 \pm 0.9 \mathrm{aA}$ \\
$\mathrm{Bb} 11510^{9} \mathrm{conidia} / \mathrm{ml}$ & $2.2 \pm 0.8 \mathrm{bB}$ & $1.5 \pm 0.2 \mathrm{bB}$ \\
$\mathrm{Bb} 11510^{7} \mathrm{conidia} / \mathrm{ml}$ & $2.9 \pm 0.3 \mathrm{bB}$ & $2.8 \pm 0.6 \mathrm{bcB}$ \\
$\mathrm{Bb} 1110^{9} \mathrm{conidia} / \mathrm{ml}$ & $4.8 \pm 0.5 \mathrm{cC}$ & $3.2 \pm 0.7 \mathrm{CC}$ \\
$\mathrm{Bb} 1110^{7} \mathrm{conidia} / \mathrm{ml}$ & $5.1 \pm 1.1 \mathrm{cC}$ & $3.6 \pm 0.4 \mathrm{CC}$ \\
$\mathbf{F}$ & 11.22 & 47.13 \\
$\boldsymbol{P}$ & $<0.0001$ & $<0.0001$ \\
\hline
\end{tabular}

In the same column, means followed by the same lowercase letter are not significantly different (between isolates comparison) (ANOVA followed by SNK test at $5 \%$ )

In the row, means followed by the same uppercase letter are not significantly different (within concentrations comparison) (ANOVA followed by SNK test at 5\%) ES standard error 
systemic resistance (ISR) is an important mechanism by which the whole plant is prepared for an enhanced defense against a wide range of insect pests (Pieterse et al. 2014). However, the effective mechanism by which the endophyte $B$. bassiana can induce defense responses in tomatoes to repel pests is still unknown.

It was also shown that the $B$. bassiana $\mathrm{Bb} 115$ isolate at a concentration of $1 \times 10^{9} \mathrm{conidia} / \mathrm{ml}$ reduced the mean survival times (MST) of third-instar $H$. armigera larvae more than the $\mathrm{Bb} 11$ isolate. The MST of the larvae decreased with the increase in fungal concentration. These results could be considered as indirect effects occurring during the consumption of the B. bassiana-colonized leaves. These indirect effects, such as the production of secondary metabolites or the induction of a systemic response in tomatoes, could inhibit larval feeding behavior. Similar results were obtained with Jaber Lara and Ownley (2017) on H. armigera fed using leaves of Vicia faba plants treated with the endophyte $B$. bassiana. Obtained findings are in agreement with Castillo Lopez and Sword (2015) who observed lower survival rates of Helicoverpa zea larvae when fed using tomato plants colonized by B. bassiana.

Thus, $B$. bassiana can reduce insect pest's damage through its endophytic colonization by inhibiting insect development. The endophytic relationship between an EPF and a plant suggests possibilities for biological control, in particular the use of fungal inocula as insecticides. In the present study, the endophytic characteristic of $B$. bassiana was proved and its effect on $H$. armigera larvae well established, confirming the usefulness of this fungal species in insect pest control.

\section{Conclusions}

The present study demonstrated the endophytic colonization of tomato plants by $B$. bassiana and its effect on the survival of $H$. armigera larvae feeding on leaves of local and improved tomato inoculated varieties. The colonization rate increased fungal concentration with seed coasting method, regardless to the fungal isolate. However, B. bassiana isolate $\mathrm{Bb} 115$ at a concentration of $1 \times 10^{9}$ conidia $/ \mathrm{ml}$ was found to be more effective with seed coasting method. Although field studies are necessary to support the obtained results, the endophytic characteristic of $B$. bassiana could be included in an integrated strategy for the management of $H$. armigera in tomato.

\section{Abbreviations}

Bb: Beauveria bassiana; $p$ : $p$ value; SE: Standard Error

\section{Authors' contributions}

JT: conceptualization, methodology, writing - original draft. YLEL, EYD, and OKDK: writing - review and editing. KZ, JA, YG, and AK: collection of the data. AD: supervision, writing - review and editing. All authors have read and approved the manuscript.

\section{Funding}

Culture media, substrates, stationary materials, and laboratory equipment were supplied by TWAS.

Availability of data and materials

All data and materials are stated in the manuscript.

\section{Declarations}

Ethics approval and consent to participate

Not applicable.

Consent for publication

Not applicable.

Competing interests

The authors declare no competing interests.

\section{Author details}

'Laboratoire d'Entomologie Appliquée, Université Nationale des Sciences, Technologies, Ingénierie et Mathématiques (UNSTIM), B.P. 14, Dassa, Republic of Benin. ${ }^{2}$ International Institute of Tropical Agriculture (IITA), 08 B.P. 0932. Tri Postal, Cotonou, Republic of Benin. ${ }^{3}$ Université Nationale d'Agriculture (UNA), 08 BP1055, Cotonou, Republic of Benin.

Received: 16 February 2021 Accepted: 5 May 2021

Published online: 12 May 2021

\section{References}

Agrios GN (2005) Plant pathology, 5th edn. Elsevier Academic Press, San Diego Akello JT, Dubois CG, Gold D, Coyne J, Paparu P (2007) Beauveria bassiana (Balsamo) Vuillemin as an endophyte in tissue culture banana (Musa spp.). $J$ Invertebr Pathol 96(1):34-42. https://doi.org/10.1016/j.jip.2007.02.004

Arnold AE, Maynard Z, Gilbert GS, Coley PD, Kursar TA (2000) Are tropical fungal endophytes hyper diverse. Ecol Lett 3(4):267-274. https://doi.org/10.1046/j.14 61-0248.2000.00159.x

Assogba Komlan F, Sikirou R, Tiémoko Y, Adanguidi J, Mensah ACG (2016) La culture de la tomate au Bénin. ISBN : 978-99919-2-124-2. Dépôt légal № 8550 du 19 Février, 1er trimestre 2016, Bibliothèque Nationale (BN), p 16

Barrionuevo MJ, Murúa MG, Goane L, Meagher R, Navarro F (2012) Life table studies of Rachiplusianu (Guenee) and Chrysodeixis (1/4/4 Pseudoplusia includes) (walker) (Lepidoptera: Noctuidae) on artificial diet. Fla Entomol 95:944e951

Castillo Lopez D, Sword GA (2015) The endophytic fungal entomopathogens Beauveria bassiana and Purpureocillium lilacinum enhance the growth of cultivated cotton (Gossypium hirsutum) and negatively affect survival of the cotton bollworm (Helicoverpa zea). Biol Control 89:53-60. https://doi.org/10.1 016/j.biocontrol.2015.03.010

Douro Kpindou OK, Djegui DA, Glitho IA, Tamò M (2012) Sensitivity of Helicoverpa armigera (Hübner) (Lepidoptera: Noctuidae) to the entomopathogenic fungi Metarhizium anisopliae and Beauveria bassiana in laboratory. J Agric Biol Sci 7:1007-1015

Herrero MI, Fogliata SV, Vera A, Casmuz A, Gómez DS, Castagnaro AP, Gastaminza G, Murúa MG (2018) Biological characterization and mating compatibility of Helicoverpa gelotopoeon (D.) (Lepidoptera: Noctuidae) populations from different regions in Argentina. Bull Entomol Res 108:108-115

Jaber Lara R, Ownley BH (2017) Can we use entomopathogenic fungi as endophytes for dual biological control of insect pest and plant pathogens. Biol control 116:36-45

Kambrekar DN, Aruna J (2018) Screening for endophytic Beauveria bassiana from different plants and its pathogenicity chickpea pod borer, Helicoverpa armigera (Hübner). J Exp Zool 21(2):727-731

Ma X, Liu X, Ning X, Zhang B, Han F, Guan X (2008) Effects of Bacillus thuringiensis toxin Cry1Ac and Beauveria bassiana on Asiatic corn borer (Lepidoptera: Crambidae). J Invertebr Pathol 99(2):123-128. https://doi.org/1 0.1016/j.jip.2008.06.014 
Magrini FE, Specht A, Gaio J, Girelli CP, Migues I, Heinzen H, Saldaña J, Sartori VC, Cesio V (2015) Anti-feedant activity and effects of fruits and seeds extracts of Cabralea canjerana (Vell.) Mart. (Meliaceae) on the immature stages of the fall armyworm Spodoptera frugiperda (JE Smith) (Lepidoptera: Noctuidae). Ind Crop Prod 65:150-158. https://doi.org/10.1016/j.indcrop.2014.11.032

Ownley BH, Pereira RM, Klingeman WE, Quigley NB, Leckie BM (2004) Beauveria bassiana, a dual purpose biocontrol organism, with activity against insect pests and plant pathogens. In: Lartey RT, Cesar AJ (eds) Emerging Concepts in Plant Health Management. Research Signpost, India, pp 255-269

Pieterse CMJ, Zamioudis C, Roeland B, and David MW (2014) Induced systemic resistance by benefical microbes. Annu Rev Phytopathol, 52:347-375

Posada FJ, Vega FE (2005) A new method to evaluate the biocontrol potential of single spore isolates of fungal entomopathogens. J Insect Sci 5:1-10

Prasad A, Syed N (2010) Evaluating prospects of fungal biopesticide Beauveria bassiana (Balsamo) against Helicoverpa armigera (Hübner): an ecosafe strategy for pesticidal pollution. Asian J Exp Biol Sci 1:596-601

Renuka S, Ramanujam B, Poornesha B (2017) Colonization of Beauveria bassiana (Balsamo) Vuillemin strains in maize (Zea mays L.) and their efficacy against stem borer Chilo partellus (Swinhoe). Biol Control 31(1):28-37

Russo ML, Pelizza SA, Cabello MN, Stenglein SA, Scorsetti AC (2015) Endophytic colonisation of tobacco, corn, wheat and soybeans by the fungal entomopathogen Beauveria bassiana (Ascomycota, Hypocreales). Biocontro Sci Technol 25(4):475-480. https://doi.org/10.1080/09583157.2014.982511

SAS Institute Inc (2003) SAS 9.2 2003. Qualification Tools User's Guide. SAS Institute Inc., Cary

Selim KA, El-Beih AA, Abdel-Rahman TM, El-Diwany Al (2012) Biology of endophytic fungi. Curr Rés Environ Appl Mycol 2(1):31-82. https://doi.org/10. $5943 / \mathrm{cream} / 2 / 1 / 3$

Statistical Package for Social Science (SPSS) Inc. 1989-2003. ftp://public.dhe.ibm. com/software/analytics/spss/documentation/statistics/20.0/fr/client/Manuals/ IBM_SPSS_Statistics_Core_System_Users_Guide.pdf-471p.

\section{Publisher's Note}

Springer Nature remains neutral with regard to jurisdictional claims in published maps and institutional affiliations.

\section{Submit your manuscript to a SpringerOpen ${ }^{\circ}$ journal and benefit from:}

- Convenient online submission

- Rigorous peer review

- Open access: articles freely available online

High visibility within the field

- Retaining the copyright to your article

Submit your next manuscript at $\boldsymbol{\nabla}$ springeropen.com 